\title{
O PROBLEMA DA CAUSA FINALIS EM OCKHAM
}

\author{
Alfredo Santiago Culleton*
}

\section{RESUMO}

Neste artigo pretendemos demonstrar que a nova compreensão de causa finalis, formulada por Ockham, inaugura uma nova postura teórica na qual se funda a crítica à teleologia da filosofia clássica e escolástica, rumo a uma mudança de paradigma. Isso vai significar, em termos heideggerianos, num novo princípio epocal, pelo qual Ockham será chamado de Inceptor da via moderna. Não acreditamos que seja Ockham único e exclusivo responsável por esta mudança, mas sim que as suas novas formulações minam seriamente uma das principais bases da tradição filosófica, qual seja a teleologia.

Palavras-chave: Ockham. Causa finalis. Teleologia. Franciscanismo. Metapolítica.

\begin{abstract}
This article aims to demonstrate that the new understanding of causa finalis formulated by Ockham inaugurates a new theoretical stance on which is founded a critique on the teleology of classic and scholastic philosophies, towards a paradigm shift. It will mean, in Heideggerian terms, beginning a new epoch for which will be called Ockham Inceptor modern track. We don't believe that it is Ockham the only responsible for this change, but that his new formulations seriously undermine one of the main bases of the philosophical tradition, which is teleology.
\end{abstract}

Keywords: Ockham. Causa finalis. Teleology. Franciscanism. Metha-politics.

*Doutor em Filosofia pela Pontifícia Universidade do Rio Grande do Sul (PUCRS). Professor do Programa de Pós-Graduação (PPG) em Filosofia da Universidade do Vale do Rio dos Sinos (UNISINOS). Assessor do bureau científico da Société Internationale pour L'Étude de la Philosophie Médiévale (SIEPM). E-mail: culleton@unisinos.br 
Um ponto da obra filosófica de Ockham, que resultará muito importante se levado às suas implicações jurídico-políticas, é o tratamento dado ao conceito de causa final. Consideramos que a mais profunda aversão e ao mesmo tempo reconhecimento, ao caráter inceptor da política de Ockham, é provocada mais pelas implicações políticas e práticas da sua filosofia primeira do que pela sua obra política.

Pretendemos demonstrar que a nova compreensão de causa final, formulada por Ockham, inaugura uma nova postura teórica na qual se funda a crítica à teleologia da filosofia clássica e escolástica, rumo a uma mudança de paradigma. Isso vai significar, em termos heideggerianos, num novo princípio epocal, que é a medida do todo de cada época, pelo qual Ockham será chamado de Inceptor da via moderna. Não acreditamos que seja Ockham exclusivamente e muito menos o puro tratamento dado ao conceito de causa final, mas sim que isso mina seriamente uma das principais bases da tradição filosófica, qual seja a teleologia. Parafraseando o professor Stein (1990, p. 44) ao apresentar o seu Heidegger, a teleologia ocupava o lugar do ser que se encontrava encoberto, esquecido e que devia ser resgatado pelo método conhecido como a navalha de Ockham, segundo o qual "os seres não devem ser multiplicados sem necessidade" ou, nas palavras do próprio inglês, "a pluralidade não deve ser colocada sem necessidade” ou “o que pode acontecer através de poucos [princípios] acontece desnecessariamente através de muitos" ou "muitas coisas são supérfluas se poucas suficientes". ${ }^{1}$

O mundo e a filosofia serão completamente outros sem promessa nem universais; a partir da incorporação desse princípio cético e individualista, Ockham muda o modelo condutor da matriz teórica da filosofia. O que ficou conhecido como a navalha amputa a teleologia da filosofia e implica uma redução para toda e qualquer pretensão de sistema, não havendo mais figuras a serem percorridas, nem teleologias a serem cumpridas.

O trabalho de Ockham se dirige contra a dogmatização do conceito de fim no sistema da alta escolástica, que parte do princípio de que tudo o que está em atividade o está em virtude dum fim: omne agens agit

${ }^{1}$ Quodlibetal VI, 10; VII, 8; Sent. I, 17.3. Cf. Spade (1999, p. 101). 
propter finem. ${ }^{2}$ Aqui o conceito de fim tem uma validade ontológica-geral que o próprio Aristóteles não havia explicitado. A causa finalis não é só uma das quatro causas que para a sua eficácia necessita das outras, mas a causa das causas, a causa aliarum causarum. ${ }^{3}$ Resulta visível que essa posição tem uma motivação teleológica: na série de causas e efeitos, tudo está ordenado visando a um último e supremo fim, em virtude do qual se busca algo. ${ }^{4}$ Desde esse ponto de vista, a causalidade do fim não constitui problema algum, só que Duns Scotus e William Ockham se perguntam em que consiste mesmo. A resposta - que não casualmente está orientada por uma reflexão aristotélica acerca das formas de influir do télos ${ }^{5}$ - é tão convincente como simples e seria aceita pela escolástica dos séculos seguintes. Como algo específico da causa finalis, Ockham sublinha o fato de que possa ser causada sem necessidade de existir externamente, in re extra, de onde se segue que o movimento para um fim não é um movimento real, mas metafórico (motio metaphorica), dado que só ocorre por meio de um agens que se representa e aspira algo. Em relação à existência de Deus, uma causa final corresponde a cada efeito da natureza, na medida em que é desejado por Deus; mas, se se prescinde de tal autoridade, isso não pode ser demonstrado racional (ex per se notis) nem empiricamente (per esperientiam). ${ }^{6}$

\section{Os Quodlibet}

Apesar de não ter seguido tão de perto Aristóteles como os seus predecessores Tomás e Scotus, ele não só desenvolveu algumas ideias do filósofo segundo novas perspectivas, e muitas vezes contra o modo como a Igreja institucional o entendia, mas, sobretudo, se considerava um fidelíssimo aristotélico. Resulta irônico que o antiaristotelismo filosófico e

\footnotetext{
${ }^{2}$ Tomás de Aquino, S. Th. I, q. 44, art. 4. Duns Scotus, Opus Oxoniense I, dist.8. q. 5, número 6; De Primo Principio, c. 2, concl. 4.

${ }^{3}$ Tomás de Aquino, S. Th. I. Q. 5, art. 2 ad a.

${ }^{4}$ Tomás de Aquino, Summa contra gent. 1.I, c. LXXV, 5.

${ }^{5}$ De gen. Et corr. I 7, 324 b 13-15.

${ }^{6}$ Ockham, W. Quodlib, IV, q. 1; Sent, q. 3; Phys. II, c. 6.
} 
teológico dos séculos XVI e XVII tenha tido muitas vezes como referência um convicto aristotélico como Ockham.

Podemos destacar que o próprio Ockham reconhecia que frequentemente a sua leitura de Aristóteles era um pouco controvertida, mas tinha certeza que Aristóteles detestava tanto quanto ele a ontologia platônica; como resultado, o Aristóteles de Ockham está livre de qualquer platonismo ou neoplatonismo que pudesse ter permeado a leitura dos comentadores islâmicos do corpus aristotélico, e que tinha sobrevivido, ainda que em pequena escala, mas em diferentes graus de significação, nos sistemas metafísicos propostos por Tomás e Scotus. Aos olhos de Ockham nenhum verdadeiro aristotélico seguiria Tomás no seu tratamento da criação ex nihilo, ou na utilização da noção platônica de participação ou ao tomar a esse e essentia como mais genérica distinção aristotélica de ato e potência. Nem consideraria como verdadeiro aristotélico alguém que, como Scotus, propusesse naturezas comuns que tenham uma especial maneira de ser e unidade em si mesmas, prescindindo da sua existência em substâncias singulares. Em inúmeras oportunidades, Ockham faz longas e detalhadas referências de capítulos e versos da obra de Aristóteles para dar sustentação às suas posições, aspirando não só a ser, mas a aparecer como um verdadeiro aristotélico.

É inegável que em Ockham abundem formulações filosóficas e teológicas que podem ser vinculadas a certo zelo antiaristotélico dos séculos XVI e XVII; por alguns traços de ceticismo a respeito de uma teologia natural e por certos limites no papel da razão em termos epistemológicos, pode ser considerado um pensador revolucionário. Nós tendemos a considerá-lo um revolucionário, se esse fosse o caso, mais em termos ontológicos do que pelo seu caráter subversivo do aristotelismo cristão, como muitas vezes lhe foi atribuído.

\section{Quodlibet IV, questio 1}

Para tratar sobre a causa final, ele introduz a seguinte questão: Todo efeito tem uma causa final diferente da sua causa eficiente? Escolheu como aliado o texto aristotélico do segundo livro da Física. ${ }^{7}$ Começa arguindo

7 194b32ss. "[cause] in the sense of end or 'that for the sake of which'a thing is 
mediante a negativa: existe ao menos um caso, o de Deus, no qual Ele é ao mesmo tempo causa final e eficiente. Assim, não é sempre que essas causas são distintas; mas, ao mesmo tempo, se a resposta fosse negativa não seria verdade que existem quatro causas diferentes para cada coisa.

Para isso, Ockham dedicara dois artigos esclarecendo que tipo de fim pode ser uma causa, ou que tipo de causa é a que se refere ao fim. No primeiro dos artigos, o autor apresenta três teses: na primeira delas, ele diz que "causalitas finis non est aliud nisi esse amatum et desideratum ab agente afficater, propter quod amatum fit effectus ${ }^{,},{ }^{8}$ de tal maneira que o efeito resultante é produzido por causa da coisa amada, em que a causalidade de um fim está em ser eficazmente amado ou desejado, e que na ausência de tal amor ou desejo o efeito não teria acontecido. Com isso, reconhece que causa final e eficiente podem ser distinguidas; na segunda tese, Ockham se dedica a defini-las, referindo-se à causa final como "esse amatum et desideratum eficaciter ab agente, propter quod amatum fit effectus" e a causa eficiente como "est essed illud ad cuius esse sive praesentiam sequitur aliud", mas destaca que essas definições podem, por vezes, corresponder, uma a uma coisa, outra, a outra e, por vezes, à mesma coisa.

O terceiro argumento desse primeiro artigo consiste em: podem ser amadas e desejadas coisas inexistentes, logo uma causa final pode ser mesmo inexistente. ${ }^{10}$ Consideramos isso surpreendente não só porque não encontramos essa conclusão em Aristóteles nem em Tomás de Aquino, mas, sobretudo, pelas implicações de um não existente para quem não acredita na preexistência.

done, e. g. halth is the cause of walking about." Utilizamos a tradução de David Ross, The works of Aristotle, Oxford 1930, por entender que a expressão sake no inglês expressa muito mais fielmente o sentido de finalidade do qual Ockham se vale. A melhor tradução para sake no português poderia ser na expressão "for God's sake",, "pelo amor de Deus".

${ }^{8}$ O Th IX p. 293. "A causalidade de um fim não é outra coisa que o ser amado e desejado por uma causa eficiente pela qual amamos tal efeito."

${ }^{9}$ Ibidem, p. 294. "Aquilo que é amado e desejado eficazmente pelo agente, de maneira que o efeito seja produzido pelo objeto amado."

${ }^{10}$ Vamos querer conectar esta causa final com os direitos humanos. 
No segundo artigo, ele tenta responder à questão: Todo efeito tem uma causa final diferente da sua causa eficiente? Condiciona a resposta ao fato de o fazer à luz da verdade da fé ou na ausência de qualquer auctoritatem, entendendo, por isso, respostas diferentes. No caso de a resposta ser dada levando em consideração a verdade da fé, o que não exime do uso da recta ratio, o resultado será que nem sempre as referidas causas são diferentes, mas sempre existe uma causa final, qual seja, Deus. Mas na segunda condição, em que não é aceita nenhuma autoridade, não se pode responder, nem por meio de proposições conhecidas per se, nem por experiência, se todo efeito tem a sua causa final, seja igual ou diferente da sua causa eficiente, "quia non potest probari sufficienter quod quilibet effectus habet aliquam causam finalem ". ${ }^{11}$ E dirá Ockham que às vezes a causalidade da causa final é diferente daquela da causa eficiente, mas que muitas vezes não o é; quando a mesma coisa é ao mesmo tempo causa final e eficiente, a causalidade não é diferente. Para Ockham, a causalidade de uma causa não é uma entidade distinta da própria causa; por isso, é forçado a sustentar, estritamente falando, que a causalidade de todas as coisas são idênticas com aquelas coisas e, consequentemente, idênticas entre si. ${ }^{12}$

A seguir, tentará responder a dois tipos de problemas. Primeiro, aos argumentos dos autores que consideram a autoridade revelada, que pensam que essas causalidades são distintas pelo fato de não serem intercambiáveis, no sentido de que se uma coisa é a causa eficiente, não significa que seja a causa final, nem o contrário. Defenderá a sua descrição de causa final "aquilo que é amado e desejado eficazmente pelo agente, de maneira que o efeito seja produzido pelo objeto amado" - de possíveis problemas, e conclui categoricamente que a existência de um fim não é requerida para que o efeito seja produzido, mas em agentes intencionais é exigido que a finalidade seja amada e desejada eficazmente. ${ }^{13}$

${ }^{11}$ P. 246 "Ao que pode ser provado suficientemente que todo efeito tem a sua causa final."

${ }^{12}$ Sobre o status ontológico da causa eficiente, Quodlibet 6. 12.

${ }^{13}$ P. 299. "Non requiritur existentia finis ad hoc quod effectus producatur; tamen in agentibus a propósito requiritur quod finis ametur et desideretur efficacitur." 
À causa final - assim definida como dependendo do amor e do desejo de um agente livre - lhe é questionado se ela é suficiente para alcançar o requisito da nobilidade, de se causa finalis est nobilior aliis causis. Ao que Ockham responde de duas maneiras. Em primeiro lugar, dirá que não todo fim actual, mas todos os fins ditados pela reta razão são mais nobres ou tão nobres como as outras causas. Por outro lado, sustenta que todas as finalidades são consideradas e apreciadas como relevantemente nobres pelo agente que as deseja. ${ }^{14}$

O segundo problema que ele quer enfrentar é aquele de que parece necessário para a razão natural que todo efeito tenha sua causa final, e o argumento que se usa para isso são as palavras de Aristóteles no segundo livro da Física 194b. Ockham iluminará o texto dizendo que o agente ao qual está se referindo o filósofo é uma vontade livre, um agente livre capaz de falhar e errar na sua própria atividade, mesmo que as circunstâncias permaneçam as mesmas. Ele distingue entre um agente livre e um agente natural para o qual não faz sentido, em termos racionais, perguntar: Por que razão faz alguma coisa? Este tipo de pergunta só cabe, de acordo com Ockham, no caso de atos voluntários.

No caso de agentes naturais, estes se movimentam do repouso para a ação quando o impedimento é removido, ${ }^{15}$ ao contrário do agente livre, que procede à ação quando intenta um fim. Essa distinção vai significar, em teoria do movimento, uma revolução, pois a natureza não é mais movida por uma causa final, mas supõe um movimento anterior que se perpetua ao ser removido o obstáculo e uma natureza que busca a preservação do movimento continuado. Essa ideia será mais bem explicitada durante a Renascença e tornada fundamento da Teoria do Estado por Hobbes, que, ao transpor a sua Filosofia Primeira para a política, considera papel único e constitutivo do soberano regrar o movimento continuado dos indivíduos. ${ }^{16}$

\footnotetext{
${ }^{14}$ P. 298. "[...] quod illud quod est causa finalis secundum rectam rationem, est nobilius aliis causis vel saltem aeque nobile, licet de facto non sit ita. Aliter potest dici quod semper finis est nobilior aliis causis vel in reputatione et appretiatione voluntatis." ${ }^{15}$ P. 300. "Agentia naturalia noviter excunt in actum de otio quando nunc est amotum impedimentum."

${ }^{16}$ Sobre movimento e Conatus, ver Watkins (1965, p. 126-130).
} 
Outra objeção que se lhe fazia era que se não existisse causa final, as coisas agiriam sem possibilidade de erro, ao que Ockham responde insistindo em que só é passível de erro, estritamente falando, o agente livre e não a natureza, dado que tudo o que ocorre na natureza ocorre naturalmente e não por erro.

Ockham concluirá essa questão salvando a existência das quatro causas, mas fazendo a seguinte distinção: há, muito frequentemente, mas não sempre, quatro causas distintas; e as quatro causas são consideradas distintas porque, sendo algo causa final de um evento, não significa que seja a sua causa eficiente ou vice-versa, como é o caso de Deus.

\section{Quodlibet IV, questio 2}

Aqui a questão é outra, qual seja, se pode ser provado pela razão natural que o poder de Deus é infinito, mas indiretamente faz referência ao problema que estamos a tratar. Diz ele:

Eu sustento que não pode ser demonstrado que tudo por causa da qual uma coisa natural atua é conhecido ou dirigido por algo... mas causas meramente naturais, que são determinadas pela sua própria natureza para um determinado efeito e não outro, não requerem ninguém para previamente conhecer e dirigi-las - no mínimo a razão natural não conclui que isso seja requerido. Por exemplo, fogo perto da madeira a esquenta, independentemente de alguém saber disso. Se perguntarem por que o fogo esquenta no lugar de esfriar, eu respondo que é natural que seja assim ... ${ }^{17}$

Vemos como na primeira sentença Ockham aceita a possibilidade epistêmica de que causas naturais atuem para uma finalidade, ainda que a vontade de nenhum intelecto agente direcione para tal fim. Não parece estar se referindo a vontades livres, dado que o exemplo utilizado é o do fogo, um agente atuando em ordem de um fim por necessidade natural; isso não significa desconsiderar o porquê de uma determinada ação, mas

${ }^{17}$ O Th IX, p. 115-116. 
a resposta para a pergunta de por que o fogo esquenta em lugar de esfriar será que o poder da causa final que constitui a sua natureza o faz ser assim.

Em termos epistemológicos, Ockham continua mantendo que não pode ser evidentemente conhecido, nem por demonstração, nem via proposições autoevidentes, nem por experiência, que agentes que agem por necessidade natural tenham uma finalidade preestabelecida pela vontade. A uniformidade natural dos processos não constitui por si mesma uma base para inferir que eles acontecem em ordem a um fim, já que podem ser adequadamente explicados pela necessidade natural e que resulta impossível provar que atuem de acordo com uma inteligência superior. ${ }^{18}$

\section{Algumas constantes}

No tratamento dado por Ockham à questão da causa final, resulta a constante importância dada à vontade do intelecto agente e à sua total falta de referência (e nem tanto de formulação) a uma teleologia natural. Encontramos também uma insistência em considerar a causa final como fundamental para explicar movimento. Se matéria e forma são as causas "internas" que constituem os compostos, as causas eficientes são, em sentido literal, aquelas que movem. A explicação é evidente: é o seu poder (virtus) que produz coisas na existência real. ${ }^{19}$

Ockham consegue pensar numa só maneira de a causa final ter um valor explicativo, qual seja, a de ajudar a explicar o movimento da causa eficiente. ${ }^{20}$ Ele apresenta o seguinte caso: o conhecimento de uma finalidade e amor ou desejo a ela dão à vontade do intelecto agente uma razão para fazer alguma coisa; e o conhecimento da finalidade e o amor a ela podem ser causas eficientes parciais da vontade eficaz do agente que deseja outra coisa. Aqui a conexão explicativa é criada pela vontade

${ }^{18}$ P. $302,307$.

${ }^{19}$ Quodlibeta IV, q. 1. (O Th. IX, 294) De Fine (O Th VIII, 107).

${ }^{20}$ Cf. Prologus, q. 11 (O Th I, 305). "Finis numquam respicit formam nec materiam nisi mediante agente, inquantum scilicet movet efficiens ad agendum [...]" "[...] illud non est causa essentialis alicuius rei a quo non dependet nec in esse in fieri; sed a tali quod non movet efficiens ad agendum non dependet res quocumque modo [...]" 
inteligente do agente atualmente buscando o fim e eficazmente desejando algo por si. Tanto no Expositio como na Summula, Ockham representa um Aristóteles que começa com uma vontade do intelecto agente e acaba por argumentar por analogia à teleologia da natureza inanimada. Para Ockham, há uma constante preocupação de que a analogia entre arte e natureza não sustente a inferência de Aristóteles, por ver duas grandes diferenças entre a vontade do intelecto agente e a natureza inanimada. Em primeiro lugar, porque esta última não tem conhecimento e não pode atuar pela razão. Em segundo lugar, o último atua por necessidade natural e atua até o limite do seu poder para produzir o seu efeito. Se o entendimento de um fim e o amor por ele disparam o desejo eficaz por uma outra coisa pela vontade do intelecto agente, não há maneira comparável para que uma não existente finalidade dispare um agente natural a atuar já que atua por si.

\section{Não existente como causa finalis}

Para poder entender melhor a passagem de Ockham segundo a qual "non requiritur existentia finis ad hoc quod effectus producatur; tamen in agentibus a propósito requiritur quod finis ametur et desideretur efficacitur", tentemos entender a sua compreensão de Ser, Essência e Existência da qual aquela depende.

Em sentido geral, o termo ens significa qualquer coisa e tudo o que é dado neste universo, seja mental ou extramental. Também podemos dizer que ens significa qualquer e todo indivíduo, se considerarmos "coisas" (res) como indivíduos. ${ }^{21}$ Para Ockham, é sempre possível transcender dos conceitos de coisas distintas e formar um conceito que seja superior a no mínimo um deles, e que possa ser predicado de ambos. Se todos os conceitos distintos são superados, a noção predicável mais comum acerca das coisas pode ser alcançada, e teremos a noção de ens. ${ }^{22}$

21 "Nunc logice loquendo tripliciter accipitur singulare et individuum. Uno modo dicitur singulare quod est una res numero et non plures res. Alio modo dicitur singulare res extra animam quae est una et non plures nec est signum alicuius. Tertio modo dicitur singulare signum proprium uni quod vocatur terminus discretus." Quodlibet V, 12.

22 Cf. Summa Logicae, 1.38 . 
Dirá Ghisalberti: “ora, ente continua sendo sempre um particípio do verbo esse, e como tal seu significado está ligado àquele do semantema ser" (GHISALBERTI, 1997, p. 119). ${ }^{23}$ Esse ente é muitas vezes utilizado pela tradição escolástica sem a suficiente delimitação. Quando Ockham se encontra com expressões como a que sustenta que a esse intelligibile ou a esse repraesentatum de uma criatura não é realmente distinta da essência divina, a mente lógica do nosso autor reage com suspeita, e as considera "irracionais", pois acredita que seja um problema mais de caráter terminológico que real. ${ }^{24} \mathrm{~A}$ fim de buscar uma terminologia apropriada, ele propõe três sentidos distintos para ser ou esse:

a) Esse pode significar existir. Neste caso, a variação verbal do termo era chamada pelos escolásticos de "secundum adiacens", que significa que ser (est) constitui todo o predicado, como na assertiva: Sócrates é; para o que normalmente se diria Sócrates existe.

b) Esse pode significar ens, no sentido de algo que não é repugnante, que seja a ordem atual das coisas.

c) Esse pode ser usado meramente como ligação numa proposição. Como tal, é o "tertium adiacens" e une o predicado com o sujeito e indica ou significa que o predicado é predicado do sujeito.

Para melhor entender o segundo dos sentidos de esse, vejamos o seguinte parágrafo da Summa Logicae:

De igual maneira, existe a distinção de ser em ato e ser em potência. Isso não significa que algo que não está no universo, mas que pode estar no universo, seja verdadeiramente um ser, ou que alguma outra coisa que esteja no universo, seja um ser. Antes, Aristóteles, ao dividir esse em potência e ato (no quinto livro da Metafísica - 1. c. 1017b 1.), tem em mente que esse substantivo esse é predicado de algo pelo

\footnotetext{
${ }^{23}$ Segue fielmente Ph. Boehner, The Metaphysics of Ockham, in Collected Articles, p. 384. 24 "Sed ista opinio videtur mihi irrationalis; quia tamen plus constat in verbis quam in re et verba sunt ad placitum et unusquisque potest vacare esse intelligibile creaturae sicut placet, ideo arguere contra istam opinionem est arguere ad nomen et non ad rem [...]" Ordinatio d. 36, q. 1, D.
} 
significado do verbo ser numa proposição meramente acerca de uma coisa no seu estado atual e de tal maneira que essa proposição não seja equivalente a uma proposição acerca de possibilidade, como em Sócrates é um ser ou brancura é um ser. Acerca de algo, no entanto, esse não é predicável a não ser numa proposição sobre o possível, ou numa proposição equivalente a uma acerca do possível; como por exemplo dizendo: o Anticristo pode ser um ser. Ou: o Anticristo é um ser em potência. E diz, no mesmo lugar, "que esse é divisível em potência e ato assim como aquele que conhece e descansa"; mas nada está conhecendo ou descansando a não ser que esteja atualmente descansando ou conhecendo. ${ }^{25}$

Podemos extrair desse texto que esse, em primeiro lugar, significa qualquer coisa que esteja no universo, desde que, numa proposição como Homem é um ser, o termo ser seja utilizado para significar uma coisa que é um homem. A proposição é verdadeira, consequentemente, se houver no mínimo um indivíduo que seja um homem. Nesse caso, o termo esse é usado para uma coisa atualmente existente, aqui e agora. No entanto, o termo esse pode também ser usado em proposições que não são do presente e que não expressam um estado de coisa atual e presente, mas que pertencem ao futuro ou ao passado, ou expressam um estado de coisa possível. Em tal caso, o termo esse também pode ser aplicado no modo de ser nos tempos passado ou futuro, ou por conter a modalidade de possibilidade. Assim, as seguintes proposições podem ser verdadeiras: esta caneta é um ser; esta caneta tem sido um ser; esta caneta vai ser um ser; esta caneta pode ser um ser. Em todos estes casos, não mudamos o sentido de ser/esse, estamos somente mudando ou alargando o leque de significações de esse ou as suas suposições.

Essas considerações sobre as funções lógicas do termo esse em proposições no passado, presente, futuro e possível, discutidas pelos escolásticos nos seus tratados sobre Appellatio, Ampliatio ou Suppositio em geral, levam Ockham a uma nova circunlocução da noção de esse. Desde que seja possível levar em consideração somente o termo esse da maneira como se dá em proposições acerca do possível (o que foi possível; o que será será possível; o que é é possível), podemos definir esse como alguma coisa

\footnotetext{
${ }^{25}$ Summa Logicae 1, 38b. Ockham-Philosophycal Writings (Edinburgh 1957), p. 90-92.
} 
que não seja repugnante de ser na ordem atual das coisas; aliquid cui non repugnat esse in rerum natura. Tomada nesse sentido, nós a chamaremos esse em uma significação ou suposição irrestrita, ou simplesmente esse na sua forma irrestrita, se está restrita a alguma coisa que está no universo aqui e agora, nós a chamaremos de esse em sentido restrito. Como conclusão, podemos dizer que para Ockham esse significa toda e qualquer coisa ou realidade no universo e isso compreende, no sentido mais amplo, aquilo que não é repugnante de ser na atual ordem de coisas. ${ }^{26}$

Ainda que de maneira resumida, vejamos agora qual a relação para Ockham entre essência e existência num indivíduo: se são a mesma coisa ou são coisas distintas na realidade; e se são duas coisas distintas no mesmo indivíduo, em que uma seja a sua essência e outra a sua existência. O texto da Summa Logicae diz:

Desde que nós tocamos no ser existente, devemos fazer uma digressão para considerar, como o ser existente está relacionado com a coisa, isto é, onde o ser de uma coisa e a essência de uma coisa são duas entidades fora da coisa, distintas uma da outra. Parece-me que não há tais duas entidades; nem que o ser existente signifique algo de diferente na coisa. Pois, se esse fosse o caso, seria ou substância ou acidente. Não é acidente porque então o ser existente de um homem seria a quantidade ou qualidade; isso é manifestamente falso, como fica claro por indução. Nem pode ser dito que seja uma substância porque toda substância é ou matéria ou forma ou um compositum de ambos, ou é uma substância absoluta. Mas se o esse é outra coisa que a da entidade da coisa, não pode ser dito que seja nada disso... ainda a razão pela qual os santos e outros dizem que Deus o sumo ser, é esta: Deus é de tal maneira ser que não pode não ser; antes, é ser de maneira necessária, e não é de um outro. A criatura, pelo contrário, é ser, de tal maneira que não é necessário que seja, dado que não é necessariamente uma coisa, e isso significa que é de uma outra coisa, como uma coisa é de uma coisa como a sua causa eficiente. ${ }^{27}$

\footnotetext{
${ }^{26}$ Ordinatio d. 36, q. 1,P.

${ }^{27}$ Summa Logicae III, 2, cap. 27. "Et quia tactum est de esse existere, aliquantulum digrediendo considerandum est, qualiter esse existere se habet ad rem, utrum scilicet
} 
Nesse texto, podemos ver que o problema da distinção entre essência e existência não é considerado por Ockham na sua Metafísica, dado que é considerado insignificante em relação à realidade. Por outro lado, a distinção entre o ser que é Deus e o ser da criatura fica clara na Metafísica de Ockham; ele se recusa a projetar diferenças semânticas ou gramaticais sobre a realidade; por essa razão, enfatiza verdadeiras distinções metafísicas que estão mais de acordo com noções transcendentais; assim ele determina o Ser que é Deus como aquele ser que ser necessariamente ou que necessariamente é, ou existe. Uma criatura não é um ser necessariamente, ou que é ou existe necessariamente. Deus é um ser para o qual não há causa para o seu ser, ou a sua essência ou existência; a criatura é um ser que no seu ser, isto é, na sua essência e existência, é dependente ou causado.

Nesse sentido, podemos dizer que Ockham admite a distinção clássica atribuída a Boecio, que diferencia "quo est" (pelo qual uma coisa é) e "quod est" (o que uma coisa é), e que muitas vezes tem sido erroneamente entendida como a distinção entre essência e existência. Não se distingue em Deus aquilo pelo qual Deus é e o que Deus é, dado que Deus é Ele mesmo por Ele mesmo. Na criatura existe esta distinção, uma distinção real como aquela entre uma coisa e outra, dado que a criatura é o que é, isto é, ele mesmo, mas é por outro, no caso por Deus.

O ser, como quididade ou essência, como aquilo que precede o ser individual de qualquer maneira, seja lógica ou natural, desaparece completamente na metafísica de Ockham.

Dessa maneira, ainda que sinteticamente, pretendemos ter mostrado no que se têm convertido algumas das noções básicas de ser depois de passar pelo conceitualismo realista de Ockham. Todas essas noções, em

esse rei et essentia rei sint duo extra animam distincta inter se. Et mihi videtur quod non sunt tália duo, nec esse existere significat aliquid distinctum a re.Quia si sic, aut esset substantia aut accidents. Non accidens, quia tunc esse existere hominis esset quantitas vel qualitas, quod est manifeste falsum, sicut indictive patet. Nec potest dici quod sit substantia, quia omnis substantia vel est matéria vel forma vel compositum, vel substantia absoluta; sed nullum istorum potest dici esse, si esse sit alia res ab entitate rei [...] Causa autem quare Sancti et alii dicunt Deum esse ipsum esse, est quia Deus sic est esse non potest non esse; immo necessário est esse nec ab alio est. Creatura autem sic est esse, quod non est necessário esse, sicut nec necessário est res, et ab alio est, sicut ab alio est res effective." 
última instância, se reúnem numa única noção de ser que significa ou a existência atual de indivíduos ou coisas neste mundo ou aquela segundo a qual não é repugnante que seja na ordem atual das coisas. Na metafísica de Ockham desaparece toda e qualquer ideia platônica, assim como vestígios de platonismo remanescentes em Aristóteles, para quem ainda essência ou quididade é algo que precede, ao menos lógica e naturalmente, ainda que não no tempo, o indivíduo. Para Ockham, o indivíduo é equiparado com a sua essência, assim como com a sua existência, e ambos são diferentes nomes para a coisa mesma, que ou é um ser na atual ordem das coisas ou alguma coisa que não resulta repugnante na atual ordem das coisas. ${ }^{28}$

O "braço" positivista do pensamento jurídico moderno - Hobbes, Gassendi, Espinosa - se separa radicalmente da filosofia tomista negando à causa final e à metafísica clássica uma ordem natural teleológica, quer ver o direito só como produto da vontade e não de uma razão que resgata o justo por meio da natureza; isso implica uma renúncia à tradição da doutrina romana. De outro lado, o braço do pensamento moderno, que pode ser chamado de escola do direito natural, desvia da doutrina tomista ao ficar aprisionado a definições rígidas de natureza humana ligadas a uma compreensão fisiológica ou mecânica de natureza. ${ }^{29}$ Já não existe uma finalidade do homem de onde se inferem intelectualmente normas morais e de direito.

Outro elemento aristotélico-tomista subvertido é a compreensão de que o homem é um animal naturalmente político, isto é, ele está chamado para a polis e, como tal, a sua natureza está fundada na sua natureza e esta no seu ser iluminado pela causa final. Para Tomás, os estados, como organizações sociais ou soberanas, são naturais e não fruto do pecado, como pensava a tradução agustiniana, por isso digno e autônomo. A lei positivada e arbitrária, no sentido de dependente de uma vontade livre e subordinada à razão, ordenada por autoridade competente, dentro de certas condições, pelo fato de precisar e completar a justiça natural, é a segunda fonte indispensável à ordem completa da justiça. Constitui o justo e obriga em consciência. Mas o mérito por excelência da doutrina jurídica tomista

\footnotetext{
${ }^{28}$ Sobre essência e existência, ver também: Quodlibet II q. 7 e q. 8

${ }^{29}$ Quodlibet V, q 10 e q. 11.
} 
é o de introduzir a necessidade natural e da autoridade da lei como fonte do direito. Diferentemente, Ockham resgata de Tomás a radicalidade da racionalidade leiga, mas deixa de lado a teleologia, que é considerada por ele mais teológica que filosófica.

\section{Referências}

AQUINO, T. de. Suma teológica. 2. ed. São Paulo: Loyola, 2003. v.9.

BOEHNER, P. The metaphysics of Ockham. In: . Collected articles on Ockham. New York: The Franciscan Institute, 1958. p. 384.

FREDDOSO, A. Introduction to the Quodlibetal Questions. Yale: Yale University Press, 1991, p. xxii.

GHISALBERTI, A. Guilherme de Ockham. Tradução de Luis Alberto De Boni. Porto Alegre: Edipuc, 1997.

OCKHAM, W. Ockham's theory of terms. Tradução de Michael J. Loux. Indiana: University of Notre Dame Press, 1974.

Ockham's theory of propositions, part II of the Summa logicae. Tradução de Alfred J. Freddoso. Indiana: University of Notre Dame Press, 1980.

. et al.(Ed.). Opera philosophica. 6 volumes New York: Franciscan Institute, 1974-1985.

. Ockham on Aristotle's physics. Tradução de Juian Davies. New York: Franciscan Institute, 1989.

. Quodlibetal questions. 2 volumes Tradução de Freddoso e Francis E. Kelley. New Haven: Yale University Press, 1991.

OFFLER, H. S. The "influence" of Ockham's political thinking. In: VOSSENKUHL, W.; SCHONBERGER, R. (Ed.). Die Gegenwart Ockhams, Weinheim, 1990. p. 338-365

STEIN, E. Seis estudos sobre Ser e Tempo. 2. ed. Petrópolis: Vozes, 1990. SPADE, P. Ockham's nominalist methafisics: some main themes. In: SPADE, P. Cambridge Companion to Ockham. Cambridge: Cambridge University Press, 1999. 
TIERNEY, B. Origins of natural rights language: texts and context - 11501250. History of Political Thought, Exeter, v. 4, n. 10, p. 615-646, 1989.

Data de registro: 10/12/2010

Data de aceite: 16/02/2011 
